\title{
Buccal swabs allow efficient and reliable microsatellite genotyping in amphibians
}

\author{
Thomas Broquet · Laura Berset-Braendli • \\ Guillaume Emaresi · Luca Fumagalli
}

Received: 2 May 2006/ Accepted: 2 June 2006/Published online: 4 August 2006

(C) Springer Science+Business Media B.V. 2006

\begin{abstract}
Buccal swabs have recently been used as a minimally invasive sampling method in genetic studies of wild populations, including amphibian species. Yet it is not known to date what is the level of reliability for microsatellite genotypes obtained using such samples. Allelic dropout and false alleles may affect the genotyping derived from buccal samples. Here we quantified the success of microsatellite amplification and the rates of genotyping errors using buccal swabs in two amphibian species, the Alpine newt Triturus alpestris and the Green tree frog Hyla arborea, and we estimated two important parameters for downstream analyses, namely the number of repetitions required to achieve typing reliability and the probability of identity among genotypes. Amplification success was high, and only one locus tested required two to three repetitions to achieve reliable genotypes, showing that buccal swabbing is a very efficient approach allowing good quality DNA retrieval. This sampling method which allows avoiding the controversial toe-clipping will likely prove very useful in the context of amphibian conservation.
\end{abstract}

Keywords Non-destructive sampling $\cdot$ Amplification success - Genotyping errors - Probability of identity · Hyla arborea $\cdot$ Triturus alpestris

T. Broquet $(\bowtie) \cdot$ L. Berset-Braendli · G. Emaresi

L. Fumagalli

Department of Ecology and Evolution, Laboratory for

Conservation Biology, University of Lausanne, CH-1015

Lausanne, Switzerland

e-mail: thomas.broquet@unil.ch
Buccal mucosal cells collected using cotton swabs have now long been used as a source of DNA for PCRbased downstream analyses in medicine, forensics, and veterinary sciences (e.g., Dickinson et al. 2001). This sampling method was more recently adopted in population studies as a basis for mitochondrial DNA sequencing and microsatellite typing (amphibians: Pidancier et al. 2003; Poschadel and Möller 2004, fish: Smalley and Campanella 2005, reptiles: Miller 2006). This non-destructive approach seems especially promising for amphibian species, which have classically involved destructive toe-clipping. Poschadel and Möller (2004) showed that mtDNA can easily be extracted from buccal swabs in a variety of amphibians, and Pidancier et al. (2003) successfully amplified nuclear microsatellite loci in four amphibian species. This alternative to toe-clipping can be particularly valuable for genetic-based analyses of rare or endangered species, not to mention the harmful consequences of removing toes (e.g., McCarthy and Parris 2004), especially in climbing species such as tree frogs. Yet it is not known to date how much nuclear DNA can be extracted from buccal swabs in amphibians, and what is the level of reliability for microsatellite genotypes obtained using such samples. Two sources of errors associated with low template DNA quantity and/or quality may affect the genotyping derived from buccal samples: allelic dropouts [ADO: one allele of a heterozygous individual is not amplified during a positive polymerase chain reaction (PCR)], and false alleles [FA: PCR-generated allele as a result of a slippage artefact during the first cycles of the reaction]. The detection of $\mathrm{ADO}$ and FA requires a comparison of the genotypes obtained using various types of samples, or a repetition experiment (multi-tube 
approach, Taberlet et al. 1996). Here we present a pilot study designed to: (i) quantify the concentration of DNA extracted from buccal swabs in two amphibian species, the Alpine newt Triturus alpestris and the Green tree frog Hyla arborea, (ii) estimate the success of microsatellite amplification and the rates of genotyping errors using such samples, and (iii) estimate two important parameters for downstream analyses, namely the number of repetitions required to achieve typing reliability and the probability of identity among genotypes.

A total of 12 individuals of each species were randomly chosen among a set of 23 populations of Hyla arborea and 20 populations of Triturus alpestris sampled in spring 2005 in Western Switzerland. DNA was collected using synthetic cotton swabs individually packaged in sterile polypropylene tubes (Milian). The buccal cavity of each individual was gently brushed to collect mucosal cells as described by Pidancier et al. (2003). Buccal swabs were kept at ambient temperature (usually around $10-15^{\circ} \mathrm{C}$ ) in the field for about one to eight hours and then stored dry at -20 or $-80^{\circ} \mathrm{C}$. DNA was extracted using a QIAgen DNeasy Tissue Kit (QIAgen) following manufacturer's protocol, with a few additional steps: samples were incubated overnight at $56^{\circ} \mathrm{C}$ in proteinase $\mathrm{K}$, and after incubation a QIA Shredder was used according to manufacturer's conditions. DNA was eluted in a $100 \mu \mathrm{l}$ volume (QIAgen Buffer AE), and stored at $-18^{\circ} \mathrm{C}$. The yield of DNA was quantified using a Nanodrop ND-1000 spectrophotometer (NanoDrop Technolodies, Inc). In the case of $H$. arborea all the available DNA in each extract was used for the repetition experiment (see below), hence the yield of DNA was estimated in this species using 12 other samples (randomly chosen in the same set of samples and processed in strictly the same conditions). DNA concentration ranged from 4.5 to $29.7 \mathrm{ng} / \mu \mathrm{l}$ (mean $\pm \mathrm{SE}=14 \pm$ $8.4 \mathrm{ng} / \mu \mathrm{l}$ ) in Hyla arborea extracts and from 2.3 to $19.5 \mathrm{ng} / \mu \mathrm{l}$ (mean $\pm \mathrm{SE}=8 \pm 4.2 \mathrm{ng} / \mu \mathrm{l})$ in Triturus alpestris extracts. These values are all in the lower range of DNA concentrations classically obtained from tissue samples, and they are several orders of magnitude higher than concentrations obtained using other non-destructive approaches (e.g., in wild chimpanzee: shed hair: $0.004 \mathrm{ng} / \mu \mathrm{l}$, plucked hair: $0.3 \mathrm{ng} / \mu \mathrm{l}$, faeces: $0.2 \mathrm{ng} / \mu \mathrm{l}$, Morin et al. 2001). It is also worth noting that two extracts from $H$. arborea toes clipped on adult frogs found dead in the field and one extract from a T. alpestris toe yielded a similar amount of DNA (respectively 15, 33 and $28 \mathrm{ng} / \mu \mathrm{l}$ ).

Two sets of 7 and 6 microsatellite loci (Table 1) previously isolated by Arens et al. (2000) and Garner et al. (2003) were respectively amplified in Hyla arborea and Triturus alpestris following author's protocols (for H. arborea markers, however, $0.625 \mathrm{U}$ of QIAGen Taq was used, and the number of PCR cycles was raised to 45). In order to estimate genotyping success in both species, we determined consensus multi-locus genotypes by repeating amplifications 8 times for each individual. Amplification success, recorded as the proportion of PCR reactions that lead to a readable genotype, ranged between 90 and $100 \%$ for all loci considered (Table 1). The rate of ADO was estimated for each locus as the ratio of the number of observed ADO on the number of positive amplifica-

Table 1 Amplification success, rate of allelic dropout, frequency of false alleles, and probability of identity in microsatellite genotypes of two amphibian species sampled using buccal swabs

\begin{tabular}{llllllll}
\hline Hyla arborea & Wha 1-20 & Wha 1-25 & Wha 1-67 & Wha 1-103 & Wha 1-60 & Wha 5-201 & Wha 5-22A \\
\hline$n$ & 96 & 96 & 96 & 96 & $93^{\mathrm{a}}$ & $93^{\mathrm{a}}$ & $93^{\mathrm{a}}$ \\
Amp suc (\%) & 94.8 & 90.8 & 95.0 & 100.0 & 100.0 & 89.8 & 0 \\
ADO rate (\%) & 0 & 0 & 0 & 0 & 0 & 0 \\
False allele frequency & 0 & 0 & 0 & 0 & 0 & 0 \\
$P_{\text {(ID)Sib }}^{\mathrm{b}}$ & $6.08 \cdot 10^{-1}$ & $4.02 \cdot 10^{-1}$ & $4.29 \cdot 10^{-1}$ & $3.89 \cdot 10^{-1}$ & $3.29 \cdot 10^{-1}$ & $5.27 \cdot 10^{-1}$ & $5.95 \cdot 10^{-1}$ \\
\hline Triturus alpestris & Ta1Caga4 & Ta3Ca8 & Ta4Ca4U & Ta1Ca1 & Ta2Caga3 & Ta3Caga2 \\
\hline$n$ & 96 & 96 & 96 & 96 & 96 & 96 \\
Amp suc (\%) & 91.7 & 95.0 & 91.8 & 91.8 & 92.9 & 89.8 \\
ADO rate (\%) & 0 & 0 & 0 & 12.5 & 0 & 0 \\
False allele frequency & 0 & 0 & 0 & 0 & 0 & $5.99 \cdot 10^{-1}$ \\
$P_{\text {(ID)Sib }}^{\mathrm{b}}$ & $2.77 \cdot 10^{-1}$ & $5.22 \cdot 10^{-1}$ & $4.95 \cdot 10^{-1}$ & $5.45 \cdot 10^{-1}$ & $3.49 \cdot 10^{-1}$ & 5 \\
\hline
\end{tabular}

Estimates are based on 12 randomly chosen individuals of each species repeatedly genotyped 8 times at each locus. $n$ is the number of amplifications used for the estimates

${ }^{a}$ In this case a problem during electrophoresis did not allow genotyping the last three samples. Only 93 amplifications were therefore used to estimate genotyping success at this locus

b Estimated in Gemini following Eq. 3 of Waits et al. (2001) 
tions of heterozygous individuals, following Broquet and Petit (2004). Only one locus experienced ADO (Ta1Ca1, Triturus alpestris), and none was affected by false alleles (Table 1).

These results were used to determine the number of repetitions needed to obtain reliable genotypes for locus Ta1Ca1 in T. alpestris case studies. Simulations performed with Gemini (Valière et al. 2002) showed that two repetitions allow obtaining $99.65 \%$ of correct genotypes, while this number reaches $100 \%$ with three repetitions. The probability of identity $\left(P_{\mathrm{ID}}\right.$, probability that two individuals drawn at random from a population will have the same multilocus genotype) is another useful parameter for analyses requiring reliable fingerprinting (e.g., individual identification or estimation of population size). The software Gemini was used to calculate $P_{(\mathrm{ID}) \mathrm{Sib}}$, a conservative estimate of this parameter (Waits et al. 2001). All loci combined, $P_{(\text {ID }) \text { Sib }}$ was estimated to $4.19 \cdot 10^{-3}$ for Hyla arborea and to $8.14 \cdot 10^{-3}$ for Triturus alpestris (locus-specific estimates are reported in Table 1). These estimates are in the acceptable range for most wildlife forensics and conservation genetics applications; yet they could be easily improved by typing one or more additional loci.

The yield of DNA extraction from buccal swabs appeared to be surprisingly high, and it allowed reliably genotyping the two amphibian species analyzed in this study. Amplification success using this type of material was also very high, and repetitions appeared to be required for one locus only. Nevertheless, pilot studies are strongly recommended as conditions may vary greatly among study cases (especially regarding locus-specific susceptibility to error). The results presented here show that one may expect buccal swabbing to be a very efficient approach allowing good quality DNA retrieval, likely to enhance genetic-based applications in the context of amphibian conservation.

Acknowledgements We are grateful to Nathaniel Valière who kindly answered our questions about the software Gemini, to Jérôme Pellet who provided $H$. arborea tissue samples, and to an anonymous referee who made useful suggestions. This work was supported by Swiss National Fund grant No. 3100A0-108100 to Nicolas Perrin.

\section{References}

Arens P, Van't Westende W, Bugter R, Smulders MJM, Vosman B (2000) Microsatellite markers for the European tree frog Hyla arborea. Mol Ecol 9:1919-1952

Broquet T, Petit E (2004) Quantifying genotyping errors in noninvasive population genetics. Mol Ecol 13:3601-3608

Dickinson JL, Sale MM, Craig JE, Mackey DA (2001) Laboratory methods in ophthalmic genetics: obtaining DNA from patients. Ophthalmic Genet 22:49-60

Garner TWJ, Schmidt BR, Hoeck P, Van Buskirk J (2003) Di-and tetranucleotide microsatellite markers for the Alpine newt (Triturus alpestris): characterization and crosspriming in five congeners. Mol Ecol Notes 3:186-188

McCarthy MA, Parris KM (2004) Clarifying the effect of toe clipping on frogs with Bayesian statistics. J Appl Ecol 41:780-786

Miller HC (2006) Cloacal and buccal swabs are a reliable source of DNA for microsatellite genotyping of reptiles. Conserv Genet DOI 10.1007/s10592-006-9120-2

Morin PA, Chambers KE, Boesch C, Vigilant L (2001) Quantitative polymerase chain reaction analysis of DNA from noninvasive samples for accurate microsatellite genotyping of wild chimpanzees (Pan troglodytes verus). Mol Ecol 10:1835-1844

Pidancier N, Miquel C, Miaud C (2003) Buccal swabs as a nondestructive tissue sampling method for DNA analysis in amphibians. Herpetolo J 13:175-178

Poschadel JR, Möller D (2004) A versatile field method for tissue sampling on small reptiles and amphibians, applied to pond turtles, newts, frogs and toads. Conserv Genet 5:865867

Smalley JV, Campanella JJ (2005) Buccal swabbing and extraction of high quality sunfish (Lepomis) DNA for use in PCR analysis. Biotechniques 38:188-192

Taberlet P, Griffin S, Goossens B, Questiau S, Manceau V, Escaravage N, Waits LP, Bouvet J (1996) Reliable genotyping of samples with very low DNA quantities using PCR. Nucleic Acids Res 24:3189-3194

Valière N, Berthier P, Mouchiroud D, Pontier D (2002) GEMINI: software for testing the effects of genotyping errors and multitubes approach for individual identification. Mol Ecol Notes 2:83-86

Waits L, Luikart G, Taberlet P (2001) Estimating the probability of identity among genotypes in natural populations: cautions and guidelines. Mol Ecol 10:249-256 